Liu Yunzhang, Chen Lizhen, Wang Jianlong*, Zhang Luyao and Ruan Jian

\title{
The cocrystal structure of 4-nitropyrazole - acetic acid (1/1), $\mathrm{C}_{5} \mathrm{H}_{7} \mathrm{~N}_{3} \mathrm{O}_{4}$
}

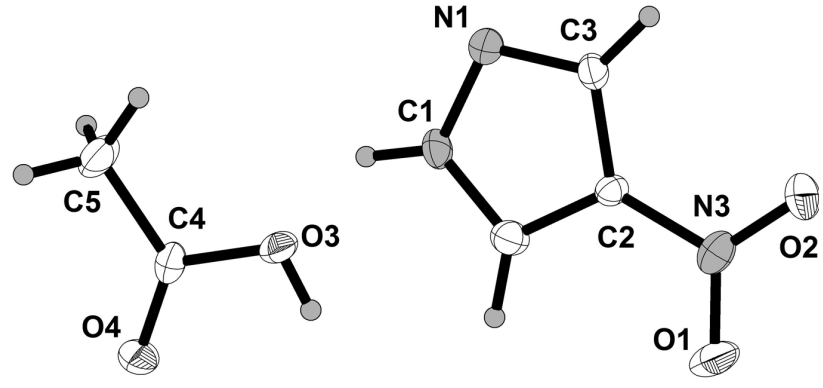

https://doi.org/10.1515/ncrs-2019-0356

Received May 18, 2019; accepted July 16, 2019; available online August 2, 2019

\section{Abstract}

$\mathrm{C}_{5} \mathrm{H}_{7} \mathrm{~N}_{3} \mathrm{O}_{4}, \quad$ monoclinic, $P \overline{1} \quad$ (no. 2), $a=5.1166(12) \AA$, $b=8.711(2) \AA, c=8.744(2) \AA \AA \alpha=103.169(7)^{\circ}, \beta=90.454(6)^{\circ}$, $\gamma=96.121(7)^{\circ}, \quad V=377.08(16) \AA^{3}, \quad Z=2, \quad R_{\mathrm{gt}}(F)=0.0619$, $w R_{\text {ref }}\left(F^{2}\right)=0.1241, T=173(2) \mathrm{K}$.

\section{CCDC no.: 1940911}

The molecular structure is shown in the figure. Table 1 contains crystallographic data and Table 2 contains the list of the atoms including atomic coordinates and displacement parameters.

\section{Source of material}

An amount of $25.9 \mathrm{~mL}$ of acetic anhydride was added to a $100 \mathrm{~mL}$ four-necked flask, cooled in an ice water bath, and $13.8 \mathrm{~g}$ of 3-nitropyrazole was slowly added to the reaction flask in batches, stirred for $10 \mathrm{~min}$, then $7.8 \mathrm{~mL}$ of fuming nitric acid was slowly added dropwise. After the addition is completed, the system is heated to $50{ }^{\circ} \mathrm{C}$, and the reaction is carried out at a constant temperature for $4 \mathrm{~h}$. After the

*Corresponding author: Wang Jianlong, School of Chemical Engineering and Technology, North University of China, Taiyuan 030051, Shanxi Province, P.R. China, e-mail:619379961@qq.com Liu Yunzhang and Chen Lizhen: School of Chemical Engineering and Technology, North University of China, Taiyuan 030051, Shanxi Province, P.R. China

Zhang Luyao and Ruan Jian: Gansu Yinguang Chemical Industry Group Co. LTD, China North Industries Group Corporation Limited, Baiyin 730900, Gansu Province, P.R. China
Table 1: Data collection and handling.

\begin{tabular}{ll}
\hline Crystal: & Colourless column \\
Size: & $0.40 \times 0.22 \times 0.17 \mathrm{~mm}$ \\
Wavelength: & Mo $K \alpha$ radiation $(0.71073 \AA)$ \\
$\mu:$ & $0.13 \mathrm{~mm}^{-1}$ \\
Diffractometer, scan mode: & PHOTON 100 CMOS, $\omega$ \\
$\theta_{\max }$, completeness: & $25.4^{\circ}, 99 \%$ \\
$N(h k l)_{\text {measured }}, N\left(h k l l_{\text {unique }}, R_{\text {int }}:\right.$ & $2798,1365,0.078$ \\
Criterion for $I_{\text {obs }}, N(h k l)_{\text {gt }}:$ & $I_{\text {obs }}>2 \sigma\left(I_{\text {obs }}\right), 785$ \\
$N(\text { param })_{\text {refined }}:$ & 116 \\
Programs: & Bruker [1], Olex2 [2], SHELX [3] \\
\hline
\end{tabular}

Table 2: Fractional atomic coordinates and isotropic or equivalent isotropic displacement parameters $\left(\AA^{2}\right)$.

\begin{tabular}{lrrrr}
\hline Atom & $\boldsymbol{x}$ & $\boldsymbol{y}$ & $\boldsymbol{z}$ & $\boldsymbol{U}_{\text {iso }}{ }^{*} \boldsymbol{U}_{\text {eq }}$ \\
\hline C1 & $0.1955(6)$ & $0.2210(4)$ & $0.1159(4)$ & $0.0223(9)$ \\
H1 & 0.3414 & 0.1743 & 0.1461 & $0.027^{\star}$ \\
C2 & $0.0827(6)$ & $0.1964(4)$ & $-0.0322(4)$ & $0.0167(8)$ \\
C3 & $-0.1250(6)$ & $0.2883(4)$ & $-0.0188(4)$ & $0.0194(8)$ \\
H3 & -0.2397 & 0.2937 & -0.1030 & $0.023^{*}$ \\
C4 & $0.6237(7)$ & $0.6508(4)$ & $0.4093(4)$ & $0.0209(8)$ \\
C5 & $0.4688(7)$ & $0.7787(4)$ & $0.4881(4)$ & $0.0320(11)$ \\
H5A & 0.3375 & 0.7364 & 0.5532 & $0.048^{\star}$ \\
H5B & 0.3798 & 0.8198 & 0.4087 & $0.048^{\star}$ \\
H5C & 0.5865 & 0.8646 & 0.5545 & $0.048^{\star}$ \\
N1 & $-0.1395(5)$ & $0.3670(3)$ & $0.1281(3)$ & $0.0248(8)$ \\
N2 & $0.0572(6)$ & $0.3237(3)$ & $0.2077(3)$ & $0.0227(8)$ \\
H2A & $0.090(6)$ & $0.358(4)$ & $0.309(2)$ & $0.027^{*}$ \\
N3 & $0.1625(6)$ & $0.0923(3)$ & $-0.1706(3)$ & $0.0240(8)$ \\
O1 & $0.3596(5)$ & $0.0259(3)$ & $-0.1604(3)$ & $0.0364(8)$ \\
O2 & $0.0302(5)$ & $0.0748(3)$ & $-0.2926(3)$ & $0.0337(7)$ \\
O3 & $0.5665(5)$ & $0.6010(3)$ & $0.2557(3)$ & $0.0256(7)$ \\
H3B & $0.663(6)$ & $0.534(3)$ & $0.221(4)$ & $0.031^{*}$ \\
O4 & $0.7883(5)$ & $0.5931(3)$ & $0.4721(3)$ & $0.0280(7)$ \\
\hline
\end{tabular}

reaction is completed, the reaction solution is poured into $200 \mathrm{~g}$ of ice water to precipitate a large amount of white solid, and the filtrate is evaporated at room temperature to obtain colourless crystals.

\section{Experimental details}

All $\mathrm{H}$ atoms were identified in difference Fourier syntheses. With $\mathrm{C}-\mathrm{H}$ bond lengths constrained to $0.95^{\circ}$ and 
$U_{\text {iso }}(\mathrm{H})=1.2 U_{\text {eq }}(\mathrm{C})$ for the hydrogen atoms of pyrazole ring, $\mathrm{C}-\mathrm{H}$ bond $0.98^{\circ}$ and $U_{\text {iso }}(\mathrm{H})=1.5 U_{\text {eq }}(\mathrm{C})$ for methyl group, $\mathrm{N}-\mathrm{H}$ bond $0.874^{\circ}$ and $U_{\text {iso }}(\mathrm{H})=1.2 U_{\text {eq }}(\mathrm{N})$.

\section{Comment}

Nitropyrazole compounds have high nitrogen content, high enthalpy of formation, high density, low sensitivity and environment-friendly characteristics, and have become a research hotspot in the field of energy-containing materials in recent years [4-6]. 3,4,5-Trinitro- $1 H$-pyrazole (TNP) is widely studied because it is the only pyrazole compound with full carbon nitrification. TNP and its derivatives can be widely used in pesticide, medicine, dye, energy-containing materials and other fields, which has far-reaching research significance and broad development prospects $[7,8]$. In order to study the synthesis mechanism of TNP, the title compound was prepared by nitrification reaction of 3-nitropyrazole, which was slowly added into acetic anhydride cooled by ice bath giving a cocrystal.

In the crystal structure of the title compound, 4nitropyrazole molecules exist in pairs with acetic acid molecules, forming a cocrystal structure. 4-Nitropyrazole molecule is often used as a ligand to form coordination compounds with certain molecules [9, 10], and the cocrystal structure of the title compound is also relevant. The bond angle between the atoms in the 4nitropyrazole molecule some what different from the bond angle between the atoms in the 4-nitropyrazole single crystal, which may be due to the presence of the acetic acid molecule and the corresponding hydrogen bond [11]. By $\mathrm{NH} \cdot \mathrm{OO}$ and $\mathrm{OH} \cdot \mathrm{N}$ hydrogen bonds two acid molecules and two pyrazole molecules are linked to a ring.
Acknowledgements: We thank the Center of Testing and Analysis, Beijing University of Chemical Technoly, for support.

\section{References}

1. Bruker. SAINT, APEX2 and SADABS. Bruker AXS Inc., Madison, WI, USA (2014).

2. Sheldrick, G. M.: Crystal structure refinement with SHELXL. Acta Crystallogr. C71 (2015) 3-8.

3. Sheldrick, G. M.: SHELXT-integrated space-group and crystalstructure determination. Acta Crystallogr. A71 (2015) 3-8.

4. Dalinger, I. L.; Popova, G. P.; Vatsadze, I. A.; Shkineva, T. K.; Shevelev, S. A.: Synthesis of 3,4,5-trinitropyrazole. Russ. Chem. Bull. 108 (2009) 2185-2185.

5. Wang, Y. L.; Zhao, F. Q.; Ji, Y. P.; Pan, Q.; Yi, J. H.; An, T.; Wang, W.; Yu, T.; Lu, X. M.: Synthesis and thermal behaviors of 4amino-3,5-dinitro-1h-pyrazole. J. Anal. Appl. Pyrolysis 98 (2012) 231-235.

6. Wu, J. P.; Cao, D. L.; Wang, J. L.; Liu, Y.; Li, Y. X.: Progress on 3,4,5-trinitro-1H-pyrazole and its derivatives. Chin. J. Energ. Mater. 24 (2016) 1121-1130.

7. Gao, H. X.; Shreeve, J. M.: Azole-based energetic salts. Chem. Rev. 111 (2011) 7377-7436.

8. Guo, J. L.; Cao, D. L.; Wang, J. L.; Wang, Y. H.; Qiao, R.; Li, Y. X.: Review on synthesis of nitropyrazoles. Chin. J. Energ. Mater. 6 (2014) 872-879.

9. Ségalas, I.; Poitras, J.; Beauchamp A. L.: Structure of 4-nitroimidazole. Acta Crystallogr. 48 (1992) 295-298.

10. Ferrer, I.; Fontrodona, X.; Rodriguez, M.; Romero, I.: Ru(II)dmso complexes containing azole-based ligands: synthesis, linkage isomerism and catalytic behaviour. Dalton Trans. 45 (2016) 3163-3174.

11. LlamasSaiz, A. L.; FocesFoces, C.; Cano, F. H.; Jimenez, P.; Laynez, J.; Meutermans, W.; Elguero, J.; Limbach, H. H.; AguilarParrilla, F.: The influence of the nitro group on the solid-state structure of 4-nitropyrazoles. Acta Crystallogr. B50 (1994) 746-762. 